\title{
Doctrinas en conflicto: Tensiones castrenses entre Augusto Pinochet y Gustavo Leigh en la "Guerra Irregular" de la dictadura chilena, 1973-1977
}

DOI: $10.46932 / \mathrm{sfjdv2n2-121}$

Received in: March 1st, 2021

Accepted in: May 30th, 2021

\author{
Gerardo Esteban Cruz Alvarez \\ Grado académico: Magíster en Historia de Chile Contemporáneo \\ Institución: Universidad Alberto Hurtado \\ Dirección: Padre León Dehon 6190 Depto. 33 \\ Correo electrónico: cruzgerard@gmail.com
}

\begin{abstract}
La presente investigación, parte de una tesis de magíster hecha por el mismo autor, busca explorar en un aspecto poco investigado en la historiografía chilena: cuáles eran las divergencias de la Junta Militar al preguntarse, en el fondo, cómo se ejerce la guerra en el marco de la dictadura chilena. Enfocándonos en los años 1973, donde la Junta se constituye a través del Golpe de Estado del 11 de septiembre, hasta el año 1977 en el que se impulsa la Consulta Ciudadana, el artículo expone como la formación prusiana de Guerra Total y la formación estadounidense de Contrainsurgencia que dieron forma al pensamiento militar chileno, se contrastan. El General Augusto Pinochet y el General Gustavo Leigh encarnarían estas diferencias, cada uno representando a una de las doctrinas bajo la que se formaron, y ahora bajo el control de facto de Chile, comenzarían a entrar en conflicto cuando se trata de tomar decisiones que afectan a la nación en el marco de la Doctrina de Seguridad Nacional.
\end{abstract}

Palabras clave: Junta Militar, Guerra Total, Contrainsurgencia, Enemigo interno, Dictadura.

\section{INTRODUCCIÓN}

Las tensiones entre el General del Ejército, Augusto Pinochet, y el General del Aire, Gustavo Leigh, fueron más allá de lo político y se explican en una diferencia doctrinal. En el marco de una presunta "Guerra Irregular" ante la que las Fuerzas Armadas instauraron su dictadura, nacen divergencias en la manera de ejercer el conflicto entre dos corrientes militares: una totalizante y armamentista que impulsa Pinochet -Guerra Total-, y otra cercana al uso del aparato político-público representada por Leigh Contrainsurgencia (COIN).

Las doctrinas previamente mencionadas manifiestan el encuentro -y desencuentro- entre dos corrientes castrenses que emergieron en temporalidades y espacios geopolíticos distintos: la Guerra Total, de inspiración prusiana y decimonónica, y la Contrainsurgencia estadounidense adaptada a la Guerra Fría. El General del Ejército mantiene un rígido alineamiento con el paradigma totalizante, el cual interpreta el conflicto bélico de forma convencional, es decir, el enemigo solo puede ser derrotado por medio de la violencia armada y el control territorial. Por otro lado, el General del Aire está adscrito a la postura norteamericana de que las guerras contra el "enemigo interno" se vencen utilizando las instituciones 
estatales, ya que, con la mejoría de las condiciones materiales de la población, los insurgentes pierden su mejor arma: el apoyo de la población ante un sistema insuficiente con sus necesidades.

Ambos paradigmas contienen una concepción diferente del campo de batalla, como también de los métodos más efectivos de combatir a un oponente poco convencional. A pesar de que el enemigo actúa en las sombras y se camufla en la sociedad civil, Pinochet sigue creyendo que el enemigo debe ser derrotado solo militarmente, mientras que Leigh apunta al fortalecimiento de la política pública. Las fuentes provienen de las grabaciones transcritas del General Leigh, manuales de entrenamiento de las Fuerzas Armadas chilenas y estadounidenses, más libros escritos por el dictador Pinochet.

\section{DESARROLLO:}

En primera instancia, cabe recalcar que, si bien este estudio no se enfoca principalmente en el Golpe de Estado del 11 de septiembre de 1973, es sin duda una piedra angular. Es en este acontecimiento donde se construye el mito acerca del conflicto explícito, el sostén de la vertiente de Guerra Total, y la “gesta militar" en la cual se apoyan los golpistas junto a sus partidarios. El despliegue escénico perpetrado por las Fuerzas Armadas -desde el asalto a La Moneda y los bombardeos en diferentes puntos-, además de la masiva cantidad de detenciones, instalan en el imaginario castrense una concepción de campo de batalla, o mejor dicho de una "gran batalla". Es el inicio de la dictadura como un espacio de excepción, que posterga a la sociedad civil y la somete a las lógicas impuestas por la Junta Militar. Esta etapa inicial militarista del régimen de facto se esbozaría:

La intervención de las Fuerzas Armadas y el derrocamiento del Presidente constitucional y de todo el régimen democrático, tuvieron todas las características de una guerra unilateral sin nadie al frente o, más precisamente, de una invasión militar. [...] Lo cierto es que el primer momento es estrictamente militar y la ideología que lo acompaña es la de la "gesta militar"1

Aunque el golpe de Estado puede ser entendido fácilmente por los militares conspiradores como parte de un acto de guerra, especialmente si consideramos lo hasta ahora expuesto sobre las influencias de la Contrainsurgencia (COIN), no es así para la población civil. Comprender fuera de los códigos militares de la Doctrina de Seguridad Nacional (DSN) las inspiraciones detrás del actuar castrense contra el Presidente Allende, es un tópico que resulta contraproducente si se pretende cooptar la simpatía más allá de la promulgación de los Bandos Militares $^{2}$. Tanto en estos últimos como en la declaración de la

\footnotetext{
${ }^{1}$ Garreton Merino, Manuel Antonio; Garreton Merino, Roberto; Garreton Merino, Carmen. Por la fuerza sin la razón: Análisis y textos de los bandos de la dictadura militar, LOM Ediciones, Santiago, 1998., p. 11-12-13.

${ }^{2}$ Los Bandos Militares fueron en el caso del Golpe de Estado del 11, un conjunto de ordenanzas promulgadas por la Junta Militar, apuntando a llenar el vacío jurídico que dejó la suspensión de la Constitución junto al cierre del Congreso Nacional. Técnicamente hablando, en el Código de Justicia Militar aprobado en 1944, los Bandos solo podían entrar en moción en tiempos de guerra y era algo exclusivo de los regimientos, con el fin de preservar el orden al interior de la tropa regular. Se sugiere leer la obra citada arriba para una profundización concisa y precisa.
} 
Junta en el ex UNCTAD III, no se percibe una mención explícita a los asuntos de Seguridad Nacional. Si contrastamos aquello con las cartas de petición ${ }^{3}$, vemos que aquí subyace este concepto en forma de una respuesta estandarizada para los ciudadanos que desean saber algo de sus familiares desaparecidos, detenidos o asesinados. Así, vemos que las influencias de la Seguridad Nacional y la doctrina que lleva su nombre quedan reservadas a un ámbito castrense, y en algunos casos, en diálogos de índole privados.

La Guerra Total pareciera ser parte del sentido común del pueblo chileno -y mundial- hasta ese entonces. Las guerras mundiales, los conflictos indochinos, las independencias del norte de África y otras tantas conflagraciones, hicieron que el conocimiento acerca de la existencia de la guerra se hiciera omnipresente. El mismo contexto de vivir en Guerra Fría con su peculiar destrucción mutua asegurada, ante los arsenales nucleares de Estados Unidos y la Unión Soviética, mantuvieron la imagen de los enfrentamientos masivos en los imaginarios colectivos. En resumidas cuentas, el paradigma de las "grandes batallas" estaba más cristalizado en la mentalidad civil que los combates insurgentescontrainsurgentes, siendo que estos dominaron la escena global en el mapa geopolítico de las dos superpotencias. En el caso de conducir un golpe de Estado bajo el supuesto violento de una Guerra Total, cuya única "particularidad" eran las maneras que el enemigo usaba para prolongar el combate -guerrilla, clandestinidad, propaganda-, era menester apelar a ese paradigma hegemónico de que solo existe un tipo de guerra, esa cuyo zenit culminó en la Segunda Guerra Mundial pero su fantasma sigue hasta el presente.

Aunque se ha destacado el rol de hacer partícipe a la sociedad civil en la presunta guerra, esto también aplicaba para la tropa regular de conscriptos, rasos y suboficiales. En Chile no hubo Guerra Total, esas batallas repartidas y disgregadas en el territorio que obligarían a la suma de los habitantes a participar, nunca llegó ${ }^{4}$. Las múltiples puestas en escena, que serán profundizadas más adelante, fueron obligatorias si es que se anhelaba convencer a la totalidad de las Fuerzas Armadas de que se estaba en un conflicto bélico. El conocido Libro Blanco ${ }^{5}$ cabe dentro de esta última descripción, pero la Junta tomó medidas con una efectividad inmediata, tal es el caso de la Caravana de la Muerte encabezada por el entonces General Arellano Stark, cuyo propósito era:

Que el envío de Arellano y sus hombres al sur constituyó la forma rápida, eficaz y sobre todo eficiente, de cómo Pinochet resolvió enseñar la línea más dura a los oficiales y cuadros permanentes del Ejército afuera de Santiago, quedan hoy pocas dudas.

\footnotetext{
${ }^{3}$ Sosteniéndonos del estudio de Leonidas Morales Cartas de Petición Chile 1973-1989, el autor recopila un conjunto de cartas enviadas de madres, esposos, hermanos, novias, entre otros, a los oficiales de máximo rango que ocupaban uno u otro territorio de Chile. Generalmente, la respuesta era que no se podía entregar información por motivos de Seguridad Nacional, algo presente en la mayoría de las misivas recogidas por Morales (las que eran respondidas).

${ }^{4}$ Rouquié, Alain. El Estado Militar en América Latina, Siglo Veintiuno Editores, México D.F., 1984, p. 288.

${ }^{5}$ Nombre completo Libro blanco del cambio de gobierno en Chile, fue un texto elaborado por el historiador Gonzalo Vial en cooperación con el Almirante Patricio Carvajal, y presentado por el Coronel Pedro Ewing. Su propósito era, a groso modo, dar evidencia de la presunta existencia de oposición armada capaz de rivalizar a las Fuerzas Armadas, usando fuentes del Ministerio de Defensa y el Ejército. Hasta el día de hoy tal libro está puesto en duda su veracidad, atribuyéndole más un propósito de Guerra Psicológica que un trabajo veraz sobre lo acaecido.
} 
Más que amedrentar a la izquierda, que ya estaba sin resistencia, la misión Pinochet-Arellano fue para meter el miedo hasta la médula de los huesos de los más corajudos oficiales, y no dejar a nadie duda de que lo que se vivía era una guerra ${ }^{6}$.

Sustentar el estado de Guerra Total no solo se relacionaba a involucrar a las guarniciones locales en ejecuciones sumarias, sino también en hacer fáctica la existencia de un enemigo. Preliminarmente, el "enemigo interno" contra el que hace su guerra la Junta es un híbrido entre la noción extranjera-foránea que le asigna el paradigma clausewitziano, sustentando que incluso si son sus compatriotas, su supuesto funcionalismo a los intereses del "imperialismo soviético" hacía que fuesen expulsados del discurso de la comunidad nacional. El sociólogo Jorge Larraín lo expone como "[...] el régimen militar pasó de la agresividad y la hostilidad a la tortura y la eliminación física del "otro" derrotado, al que ya no se le consideró parte de la comunidad nacional"7. Este último enunciado es clave, pues la expulsión de la comunidad ejercida sobre otros con los que se comparte el mismo status ciudadano y nacionalidad, resultaba fundamental para poder cargar al "enemigo interno" de esa visibilidad y hostilidad ajena propia de los contrincantes convencionales en la Guerra Total.

La antropóloga Vilma Franco establece que "lo que es político en la guerra no son los motivos esgrimidos para justificar el recurso de la violencia, como tampoco la lucha militar en sí misma, sino la decisión sobre quién es el enemigo" ". La entidad a la que se le declara el conflicto representa, como hemos dicho, un conjunto de propiedades que se contraponen directamente a lo que el "defensor" atribuye como un atentado mismo a su existencia. En la dictadura circularon varias ideas, teorías o propuestas destinadas a enaltecer la lucha anticomunista, con tal de profundizar en la cualidad amenazante que el marxismo representaba para el régimen. Darle esa connotación permitiría definirse no solo en un nacionalismo castrense, con una monopolización de las concepciones de la nación y de "lo chileno", sino también en base a lo que "no son". Dicho de otro modo, asignar la carga anti-valórica depende exclusivamente de un solo bando, este teniendo la ventaja de poder definirla y redefinirla conforme al escenario contingente, agregando, restando o reincorporando tales denominativos que lo hacen constitutivo de un "enemigo mortal".

El enemigo, evidentemente, no puede contra-argumentar sobre la forma en que está siendo caracterizado, ya que en el paradigma de la Guerra Total cada bando beligerante posee un lugar de enunciación indisputable en el espacio público, sea por la cantidad de recursos que dispone como por la posición institucional que ostenta. Esta unilateralidad retórica permite que las definiciones sobre el enemigo fluyan sin oposición ni contestación, pudiéndose erigir sin problemas satanizaciones,

\footnotetext{
${ }^{6}$ Escalante, Jorge. La misión era matar: El juicio a la caravana Pinochet-Arellano, LOM Ediciones, Santiago, 2000, p. 30.

${ }^{7}$ Larraín, Jorge. Identidad Chilena y el Bicentenario. Centro de Estudios Públicos (CEP), Santiago, 2010, p. 22.

${ }^{8}$ Franco Restrepo, Vilma Liliana. Guerras civiles: Introducción al problema de su justificación. Editorial Universidad de Antioquía, Medellín, 2008, p. 52.
} 
caricaturizaciones y manipulaciones de la información. Conocidos son los mitos acerca de los "comeguaguas", "vendepatria" u otras formas de significar al oponente con tal de que en el discurso público, se levante una aversión visceral al comunismo capaz de fomentar el apoyo civil a la dictadura. Incluso se llegó a barajar la idea de la sinarquía entre ciertos elementos militares para poder contextualizar el conflicto global, en donde “[...] existía una confabulación judeo-masónica-marxista para uniformar la vida de los pueblos del mundo, arrasando para ello con cualquier vestigio de tradición o de cultura locales"9.

La monopolización del discurso nacional tiene un efecto crisológico cuando se establecen situaciones de crisis, en las que la denominada comunidad y su Estado Nación peligran factual o artificialmente. José Bengoa se refiere a esto de la siguiente manera:

Es interesante señalar que en el momento que se sobredetermina un elemento cultural en medio de una situación de crisis, se estereotipa de tal suerte el discurso identitario que es irreconocible por parte de un importante grupo o sector de ese mismo colectivo. Sin embargo, las estructuras de poder imperantes hacen de ese discurso, el discurso dominante. La memoria es recuperada a partir de ese principio de ordenación. ${ }^{10}$

Este postulado del antropólogo chileno hace tándem con lo que él llama un efecto de sobredeterminación, donde en los conflictos bélicos el discurso nacional resuena de manera supremacista combinado con supervivencia, arrojando como el único mecanismo de cierre la aniquilación del enemigo $^{11}$. No resulta sorprendente, entonces, que, por ejemplo, en el Bando $\mathrm{N}^{\mathrm{o}} 26$ se hable de la "rendición de 150 cubanos extremistas e incautación de gran cantidad de armamento"12, pues es este tipo de detalles en las declaraciones, sumado a muchas otras que abundan en los mecanismos de difusión de la Junta, las que fomentan la idea de una invasión que emplea estrategias de infiltración y subversión. Todo esto suma al objetivo de propagar la atmósfera de guerra, resaltar los nacionalismos articulados desde los militares golpistas, y solidificar la posición de la Junta Militar frente a civiles y otros oficiales castrenses.

Dentro de ese ejercicio de apropiación de lo nacional inmerso en la sobredeterminación, resalta la capacidad que tienen las autoridades de facto por discernir quién es enemigo según sus prácticas manifiestas en el espacio público. En otras palabras, ciertas actividades como la sindicalización, la protesta, la difusión propagandística, o cualquier otra que sea vinculada con la izquierda, es tomada como un indicio de insurgencia ergo, un supuesto individuo proclive a la "incursión internacional". Debido a la

\footnotetext{
${ }^{9}$ Salazar, Manuel. Contreras: Historia de un Intocable, Uqbar Editores, Santiago, 2014, p. 65.

${ }^{10}$ Bengoa, José. La Comunidad Reclamada. Identidades, utopías y memorias en la sociedad chilena actual, Catalonia Ltda., Santiago, 2006, p. 94.

${ }^{11}$ Íbid., p. 93.

${ }^{12}$ Garreton Merino, Manuel Antonio; Garreton Merino, Roberto; Garreton Merino, Carmen. Op. Cit., p. 81.
} 
flexibilidad conceptual con la que es interpretada la acción, permite ejercer el concepto del "enemigo interno" encima de cualquiera que las haga con todo su paquete de apelativos negativos y "antiéticos". Esto extiende la legitimidad de la represión castrense más allá de la izquierda militante activa, ya que no se trata solo de aprehender o neutralizar a quienes están identificados según su participación política, sino se procede según las actividades en las que incurran, pues “[...] el programa identifica como comunista a todo movimiento "izquierdista", "populista", "neutralista", "tercermundista”, de "disidencia" o de mera "protesta"13.

La plasticidad con la que puede ser empleado el "enemigo interno" es sin duda conveniente para los militares. En general, el discurso abierto sobre el enemigo en tiempos de guerra debe ser así, en una suerte de norma universal para las Fuerzas Armadas posterior al siglo XIX. Dicha apertura posee una doble transversalidad: debe abarcar a todos los compatriotas de la comunidad omitiendo sus diferencias de clase, étnicas y políticas, sobredeterminando la superación del estado crítico encima de las problemáticas previas a nivel país o local. Por otro lado, la cantidad de cargas negativas -anti-valores, inmoralidades, antiéticos- con la que se construye e imagina al enemigo, da pie para que un individuo que se acerque, según la normalidad impuesta, a las actitudes o actividades que determinan a ese "otro hostil", pueda ser ingresado a la categoría de oponente. El discurso nacional en tiempos de guerra otorga estas facilidades a la elite de turno, es flexible pero al mismo tiempo categórico, y la oscilación depende de los intereses que establezcan en cuanto a proyecciones nacionales. Esto lo podemos ver en torno a la manera en que la dictadura asigna un rol fundamental a los trabajadores - profesionales y obreros- en el marco del Golpe de Estado, específicamente en el Bando N³1:

[...] la Patria precisa del concurso de sus profesionales, empleados, obreros y campesinos, quienes unidos en el anhelo común de forjar un Chile grande y libre, confiando en la conducción patriótica de las Fuerzas Armadas y Carabineros, constituirán el baluarte y fundamento de la reconstrucción nacional. [...] Solo la unidad nacional salvará a Chile de la autodestrucción y rescatará a su pueblo de la degradación a que lo conducía el comunismo. [...] Trabajador chileno: la reconstrucción nacional ha comenzado y tú tienes un papel que cumplir en ella. ${ }^{14}$

Tomando la cita previamente expuesta, se vislumbra la determinación del régimen por incorporar a un proyecto nacionalista al espectro trabajador, en su sentido amplio. Sin embargo, el Bando hace mención de lo que es dicho actor social en cuanto a su labor productiva, tomando el fundamental pilar que cimenta para los propósitos del desarrollo. En este sentido, el trabajador es un elemento que contribuye a la lucha contrainsurgente a partir del crecimiento económico, en su posición organicista que le atribuye la Junta Militar. Por lo tanto, su valor como segmento acoplado a la realidad nacional se condice con lo

\footnotetext{
13 Tapia Valdés, Jorge A. La Doctrina de Seguridad Nacional en el Cono Sur. El Terrorismo de Estado. Editorial Nueva Imagen, México D.F. 1980, p. 90.

${ }^{14}$ Ibid, p. 85.
} 
dicho por Carl Schmitt respecto a la gloria militar ${ }^{15}$, de traspasar la honra del deber patriótico a las asignaciones no armadas y que por el hecho de "ser chileno", claman por un deber concebido antonomásticamente en lo que le exige su condición nacional. Así, la chilenidad adopta un valor totalizante en la medida de que el discurso que la gravita suena con mayor resonancia ante un período de crisis.

La constitución del enemigo contra el cual se enfrentó el golpe tiene un grado de ficción retórica que hasta este momento, hemos visto que es no menor. Según el estudio de J. Patrice McSherry, "los análisis de inteligencia de los Estados Unidos del decenio de 1970 reconocían que ninguna fuerza guerrillera en América Latina tenía la fuerza suficiente como para poner en peligro, seriamente, a ningún gobierno" $"$. A nivel subcontinental, las pocas insurgencias armadas con capacidad de fuego estaban sometidas a condiciones se sobrevivencia frente al aparato militar y represivo, incapaces de alcanzar las experiencias de inspiración africana, asiática o directamente cubana. No obstante, el imaginario bélico posicionado en una guerra perseveró permanentemente en las lógicas golpistas. Los alcances de la DSN en el caso chileno nutren esta idea, ya que

[...] ha provocado en los militares una real fobia contra las ideas de izquierda y la gente que las sostiene, una fobia basada en la presunción de que uno de los principales objetivos de los movimientos progresistas es la liquidación de las instituciones militares. Para el soldado, en consecuencia, la lucha antisubversiva se presenta como una guerra de autodefensa y autopreservación. ${ }^{17}$

Más concretamente, el ejemplar del 18 de septiembre de 1973 del diario El Mercurio, medio con una evidente tendencia derechista y proclive a la intervención castrense, divulga una noticia titular en la que habla de un supuesto complot del gobierno de la Unidad Popular para asesinar a los altos mandos de las Fuerzas Armadas y Carabineros ${ }^{18}$. Esta complicidad de sectores civiles -recordemos lo comentado del Libro Blanco- y el mismo mando central de la Junta Militar son parte de un gran operativo psicológico, que como establecen las definiciones vistas a partir de los Field Manuals son uno de los pilares fundamentales para, además de presionar al enemigo, generar recursos en términos de adhesión civil al posicionar a los militares en una situación también de legítima defensa, apelando a los sentidos de supervivencia más elementales ergo más familiarizados en las sociedades humanas.

\footnotetext{
${ }^{15}$ Esta idea perteneciente al jurisprudente alemán en su libro El concepto de lo político, se refiere a que la contribución al esfuerzo de guerra es una tarea que depende también de la sociedad civil, en la medida que la producción, estabilidad y difusión son tan fundamentales como el combate mismo. Es por ello que la gloria marcial es replicada en trabajadores de los múltiples rubros y bases formativas.

${ }^{16}$ McSherry, J. Patrice. Los Estados depredadores: la Operación Cóndor y la guerra encubierta en América Latina, LOM Ediciones, Santiago, 2014, p. 61.

${ }^{17}$ Tapia Valdés, Jorge A. Op. Cit., p. 91.

${ }^{18}$ Lagos, Claudia. El Diario de Agustín, LOM Ediciones, Santiago, 2009, portada.
} 
Con tal de acentuar la expulsión de los "insurgentes" -y de cualquiera que sea acusado de serlo según sus prácticas o palabras- de la comunidad nacional, el Golpe de Estado declara que su guerra es contra el Comunismo Internacional, esta gran coalición de países alineados bajo el "imperialismo rojo" de la Unión Soviética. Resulta ser una herramienta moral poderosa, pues es capaz de hacer aún más vinculable el supuesto estado de guerra con la realidad cotidiana, es decir, le da una connotación explícitamente extranjera al oponente que combatieron, mucho más cercano en el imaginario colectivo que las conceptualizaciones contrainsurgentes originarias de la COIN. Junto con alimentar la "gesta militar" al erigirse como una nación que, en cierto modo delirante, derrotó a la URSS, prolongan la hegemonía militar en la administración gubernamental-estatal bajo una concepción de que esta sería una de las muchas batallas contra el Comunismo Internacional, algo que el estudio del Padre José Comblin plasma:

Creen que desde ese momento [Golpe de Estado] esta conspiración está siempre activa: las declaraciones de la Comisión de los Derechos Humanos de las Naciones Unidas, los movimientos de protesta en Europa Occidental, los discursos de los senadores americanos sobre la situación chilena, la supresión de la ayuda militar por el Congreso norteamericano, todo esto está montado por la Unión Soviética y el comunismo internacional y es la continuación de la guerra que la Unión Soviética hace a Chile; porque la Unión Soviética no ha aceptado su derrota. ${ }^{19}$

Los discursos belicistas de la Junta, el monopolio de la violencia del Estado contra sí mismo, y el anticomunismo casi paranoico de los militares de Seguridad Nacional, derivan en que lo que sucedería al Golpe -la consolidación de la dictadura- estaría acompañado de esta retórica de una guerra híbrida entre la Total y la Contrainsurgente. El protagonismo que adopta la erradicación física del enemigo se transformaría en una constante, en un interminable pero glorioso conflicto que daba un lugar privilegiado en la sociedad a los uniformados ${ }^{20}$. Cabe destacar que uno de los argumentos base de los militares, la eliminación de las guerrillas y cualquier otra manifestación de insurgencia, elevará sus niveles de hostilidad aplicada hasta que la desconfianza por la democracia sea absoluta, es decir, los mecanismos propios de tal tipo de régimen serán canalizados como espacios propicios para la formación de elementos amenazantes. Del mismo modo, la expansión de la violencia sistemática hacia sectores no armados -los que constituyen una gran mayoría de las víctimas de la represión-, evocó en que "los militares demostraron que sus objetivos estratégicos eran mucho más amplios que la simple eliminación de las guerrillas" 21 .

\footnotetext{
${ }^{19}$ Comblin, José; Methol, Alberto. Dos ensayos sobre seguridad nacional. Arzobispado de Santiago - Vicaría de la Solidaridad, Santiago, 1979, p. 125.

${ }^{20}$ Íbid, p. 126.

${ }^{21}$ McSherry, J. Patrice. Op. Cit., p. 63.
} 
Estos objetivos, que se tradujeron en la reestructuración del Estado que estaba ejerciendo ilegítimamente la Junta Militar, están directamente vinculados con el abordado binomio seguridaddesarrollo. La compenetración o crecimiento de las insurgencias, tal como ha tratado la COIN en sus materiales escritos, y según lo concebido por la idea criolla de la Seguridad Nacional, es sin duda facilitada, fomentada o nacida de condiciones materiales decadentes a escala colectiva. La permanencia del régimen de facto a partir del pensamiento militar de la DSN, se legitima en parte por la supuesta necesidad de mejorar el estado socioeconómico paupérrimo que dejó la Unidad Popular. Ya no se trata de operaciones de "búsqueda y destrucción"22 según los protocolos militares contrainsurgentes, sino de adoptar la política pública como un pilar constitutivo de esta presunta guerra, tal como establece el $F M$ 41-10 Civil Affair Operations. Sin embargo, la Junta asume además el deber de impulsar una recuperación económica en Chile, no solo con ese propósito estadounidense, sino con el objetivo de impulsar un desarrollo que trascienda un fin restaurativo. El Bando $N^{\circ} 36$ establece que:

Para superar el estado de postración económica del país debe restablecerse el proceso productivo a la brevedad. [...] El aumento de la producción y la productividad son imperativos dramáticos de nuestra patria, que plantean a los trabajadores un desafío que les corresponde asumir con espíritu de chilenidad y sacrificio. ${ }^{23}$

El General Pinochet mantiene un concepto que solo emplea al interior de las autoridades militares para explicar y promover el discurso de esta guerra prolongada: subversión latente. A groso modo, la explica como "si no estuviera la mano dura del Gobierno, aparecería de inmediato la acción subversiva y violenta, más violenta de lo que se imaginan. Aquí [Chile], si no estuviera la aplicación de los estados de emergencia, también afloraría" ${ }^{24}$. En el mismo contexto donde Pinochet esgrimió tales palabras, el Almirante Merino manifiesta su respaldo a la teoría al decir que esto es un problema mundial. Enrique Ortuzar, también presente en dicha reunión, profundiza la noción a modo aclarativo para quienes tengan dudas, explicitando que este tipo de agresión es extranjera e interna al mismo tiempo gracias al subterfugio y el sigilo característico de la insurgencia ${ }^{25}$.

Ahora bien, es menester destacar que en el conjunto de las proclamas castrenses pareciera subyacer una confusión conceptual, en cuanto a los tipos de insurgentes en la COIN. Ejercer apelativos por ejemplo

\footnotetext{
${ }^{22}$ Este tipo de operativos, profundizados en clave COIN en la serie de materiales lectivos estadounidenses FM 31-21 Guerrilla Warfare and Special Forces Operations (Guerra de Guerrillas y operaciones de Fuerzas Especiales), establecen los procedimientos para encontrar focos insurgentes armados, preparar una estrategia sigilosa, y luego proceder a su neutralización. Lo que busca es asestar golpes duros e incapacitantes a la infraestructura combativa del enemigo, anulando sus habilidades de mando, comunicación y aprovisionamiento. La DSN, en cambio, emplea este tipo de tácticas hacia sectores subversivos -fase no armada-, con tal de desmantelar violenta y abusivamente la organización política de la insurgencia, siendo que la COIN establece mecanismos divergentes para lidiar con este tipo de opositores.

${ }^{23}$ Garreton Merino, Manuel Antonio; Garreton Merino, Roberto; Garreton Merino, Carmen. Op. Cit., p. 88.

${ }^{24}$ Secretaría Junta de Gobierno. Acta $N^{o}$ 281-A, Santiago, Septiembre de 1976, p. 50.

25 Íbidem.
} 
"subversivos", "terroristas", o "extremistas", inmerso en el mismo discurso beligerante de la Junta Militar, presenta la imagen de que hacen más de sinónimos entre sí que de categorías para buscar aplicar distintos protocolos según el caso. Dicho de otro modo, la retórica marcial del golpismo introduce en el "enemigo interno" lo que para la COIN se entendería por insurgentes, el término general para expresar todas las formas de contrahegemonía -armadas, culturales, políticas, civiles-. Mientras el paradigma estadounidense, más afín con el General Gustavo Leigh, apunta a que esta clasificación variopinta es necesaria con el fin de una mejor planificación contextual, los militares chilenos de la DSN lo usan para generalizar y darle la misma connotación de amenaza a la integridad del Estado Nación, cuya respuesta debe ser de naturaleza puramente militar, violenta y represiva.

No obstante, aunque el rasgo indiscriminado del "enemigo interno" hace que todos quienes se les cargue tal nominación, son objetivos de la erradicación física por su condición de amenaza "obliteradora", vemos que la máquina de guerra de las Fuerzas Armadas y Carabineros en el ejercicio de esta violencia tiene múltiples prácticas. El hecho de que por ejemplo el MIR haya sido uno de los movimientos que sufrieron una intensidad severa en la guerra contrainsurgente, tiene asidero en poseer un discurso revolucionario de lucha armada acentuado y público a diferencia de la Unidad Popular, por lo tanto su tipificación insurgente es mayor. Cayendo en una ambigüedad entre las categorías de subversivo y guerrillero, los militantes miristas se aproximaron mucho más a ser una "amenaza táctica" a ojos de las Fuerzas Armadas. Al ser más cercanos a la insurgencia guerrillera, su trato es ahora en la condición de soldado-soldado, y no de soldado-cooperador como en el de los partidarios dirigenciales de la UP. Incluso en el centro Chacabuco, el exprisionero Sadi Renato relata "Caminamos por las canchas sin vendas y pasamos frente a las oficinas de interrogatorio. Están cerradas, son tres y una de ellas está dedicada al MIR. Se les ha quedado corrida la cortina de género que cubre la ventana. Con disimulo miramos y vemos que hay un organigrama de la directiva nacional, regional y local del MIR"26.

En cuanto al empleo del aparato estatal con miras a causar desafección en los insurgentes, la oficialidad chilena es categórica en ponerla en un plano separado a la derrota de los enemigos. Como bien se dijo, la COIN e incluso la TGR de Galula enfatiza que sin una política pública proactiva dedicada a la mejoría de las condiciones materiales de la población, la lucha contrainsurgente no tendría una real chance de vencer; por otro lado, la DSN chilena mantuvo posturas muy divergentes en su interior. Si tomamos a la Junta Militar en forma de ejemplo, el General del Aire Gustavo Leigh sostuvo una acalorada discusión con el General Pinochet en septiembre de 1977, donde el primero criticaba la prolongación del Estado de Sitio que solo terminaba por erosionar la imagen internacional y profundizar la privación individual, mientras que Pinochet defendía una política de Seguridad Nacional dura en la que "seguir apretando" era

\footnotetext{
${ }^{26}$ Joui Joui, Sadi Renato. Chacabuco y otros lugares de detención, Narrativa Punto Aparte, Valparaíso, 2014 , p. 135.
} 
el mecanismo principal de combate ${ }^{27}$. En ese mismo connato, Leigh expresaba ser proclive a hacer las cosas "a la europea", refiriéndose a la paulatina apertura del Estado de Derecho y el fortalecimiento del Estado en beneficio de los sectores bajos, de lo contrario se estaría "pavimentando el camino a los marxistas" 28 . Es màs, la Declaración de Principios de la Junta Militar muestra una abierta sintonía con la teoría de la modernidad que sostiene la COIN:

Un importante sector de la humanidad, llamado subdesarrollado o en vías de desarrollo, sufre el impacto de millones de seres humanos que se debaten en la pobreza, cuando no en la miseria. Aunque no en sus peores grados, Chile integra este primer grupo. Desde él se ha mirado alternativamente a dos tipos antagónicos de sociedades como modelos posibles hacia los cuales encaminarnos, con el objeto de superar la situación descrita. Unos miran hacia las sociedades llamadas socialistas e inspiradas en el marxismo-leninismo, al paso que otro anhelan un desarrollo económico compatible con la justicia social y la libertad política, semejante al que han alcanzado las naciones más avanzadas de occidente. ${ }^{29}$

Mejorar la economía nacional y enfrentar a la insurgencia se ven como un tópico aparte en ciertos militares golpistas. En el párrafo anterior, Leigh -que luego sería respaldado por Merino tal como aparece en sus memorias Bitácora de un Almirante- enfatiza en esa política pública, al mismo tiempo que Pinochet recalca en la intensificación de la fuerza como el único recurso viable. Independiente de los detalles en esos contrapuntos, se visualiza un objetivo común: contrarrestar al marxismo. Podríamos decir que el Comandante en Jefe del Ejército se mostraba cercano a la vertiente "trinquierista" de la TGR ${ }^{30}$, en la medida que el enemigo "terrorista" representa una amenaza tal que la fuerza es un mecanismo de respuesta proporcional y completo. Leigh y Merino, ambos con estudios militares en academias estadounidenses, apoyan más bien que el fortalecimiento del desarrollo económico y las garantías ciudadanas son la clave estratégica $^{31}$, estando directa o indirectamente en mayor concomitancia con lo estipulado en la rama COIN de Civil Affairs.

Así vemos que las fuerzas de seguridad del régimen, que encarnan un discurso de Guerra Total con métodos de la Guerra de Contrainsurgencia, mantienen una posición de discriminación selectora sobre los "enemigos internos" que detienen, capturan o ejecutan. Esto presenta una dualidad pragmática, es decir, aunque la retórica dictatorial apela a lo altamente peligroso que es este rival sigiloso, ramifica sus

\footnotetext{
${ }^{27}$ García de Leigh, Gabriela. Leigh. El General Republicano, Ediciones GLG E.I.R.L., Chile, 2017, p. 169.

${ }^{28}$ Íbidem.

${ }^{29}$ Junta de Gobierno, Declaración de Principios 11 de Marzo, Gobierno de Chile, Santiago, 1974, p. 1.

${ }^{30}$ TGR significa Teoría de la Guerra Revolucionaria, desarrollada por el francés Coronel Roger Trinquier en su experiencia durante la Guerra de Independencia de Argelia. A groso modo, combina el discurso totalizante de la Guerra Total pero incorporando elementos característicos de la Contrainsurgencia, pero funcionando bajo el binomio orden-terrorismo en vez de orden-insurgencia.

${ }^{31}$ Aunque los dos miembros de la Junta Militar estaban de acuerdo en esta generalidad, a finales de los 70’ se cristalizarían las divergencias en lo que ambos entienden por el "desarrollo económico" orientado a derrotar al marxismo. El Almirante Merino tendería a abrazar posturas neoliberales duras, mientras que el General Leigh seguiría sosteniendo su idea de aumentar el poder civil del Estado. Sugiero leer el texto del historiador Manuel Gárate, La Revolución Capitalista de Chile, para quien desee adentrarse en tal debate.
} 
prácticas de represión y violencia según una amplia gama de factores. Los Campos de Prisioneros son un gran expositor de este fenómeno, pues a pesar de las inhumanas privaciones y groseros abusos contra los internos, debemos dejar en claro que no eran Campos de Exterminio en el sentido estricto de la palabra. Sin embargo, siguen siendo una herramienta de neutralización para los militares, pues los Campos de Prisioneros son un rasgo característico en los escenarios bélicos donde independiente de las dinámicas que cada escenario particular tenga, en todos los casos hay un enemigo capturado que está incapacitado y anulado por el cautiverio.

\section{CONCLUSIÓN:}

Para 1977, al haber impulsado una Consulta Ciudadana sin la aprobación de los otros miembros de la Junta Militar, Pinochet logró dar una falsa legitimidad a su mandato dictatorial. Los otros dos miembros de la Junta Militar, el Almirante Toribio Merino y el General de Carabineros César Mendoza, aceptaron -de mala manera- tal resultado, pero no así el General Leigh. Su férrea oposición a los designios del General del Ejército le costaría su posición dentro de la Junta, siendo destituido en 1978 por sus pares de las otras ramas armadas quienes, supuestamente, no podían expulsarse unos a otros.

Su retirada y reemplazo por el nuevo General del Aire, Fernando Matthei Aubel, significarían la derrota política y doctrinaria de la Contrainsurgencia en suelo chileno. Sin el contrapeso que demandaba más presencia estatal, uso del aparato público civil y una mejoría de las condiciones materiales de la ciudadanía, la Guerra Total se impone al alero del surgimiento neoliberal que seguiría a Chile desde la década del 80, esta vez mezclando lo totalizante de la doctrina prusiana con la privatización masiva de derechos fundamentales y propiedad pública. Esos recursos, según la lógica de la COIN, podrían haber sido empleados en otorgar beneficio y desarrollo a la población más carente, evitando así darle razones para que vean al marxismo como un canal que recoge y promete sus demandas populares. 


\section{BIBLIOGRAFÍA}

1. Bengoa, José. La Comunidad Reclamada. Identidades, utopías y memorias en la sociedad chilena actual, Catalonia Ltda., Santiago, 2006

2. Comblin, José; Methol, Alberto. Dos ensayos sobre seguridad nacional. Arzobispado de Santiago - Vicaría de la Solidaridad, Santiago, 1979

3. Escalante, Jorge. La misión era matar: El juicio a la caravana Pinochet-Arellano, LOM Ediciones, Santiago, 2000

4. Franco Restrepo, Vilma Liliana. Guerras civiles: Introducción al problema de su justificación. Editorial Universidad de Antioquía, Medellín, 2008

5. García de Leigh, Gabriela. Leigh. El General Republicano, Ediciones GLG E.I.R.L., Chile, 2017

6. Garreton Merino, Manuel Antonio; Garreton Merino, Roberto; Garreton Merino, Carmen. Por la fuerza sin la razón: Análisis y textos de los bandos de la dictadura militar, LOM Ediciones, Santiago, 1998

7. Joui Joui, Sadi Renato. Chacabuco y otros lugares de detención, Narrativa Punto Aparte, Valparaíso, 2014

8. $\quad$ Lagos, Claudia. El Diario de Agustín, LOM Ediciones, Santiago, 2009

9. Larraín, Jorge. Identidad Chilena y el Bicentenario. Centro de Estudios Públicos (CEP), Santiago, 2010

10. McSherry, J. Patrice. Los Estados depredadores: la Operación Cóndor y la guerra encubierta en América Latina, LOM Ediciones, Santiago, 2014

11. Pinochet Ugarte, Augusto. Camino Recorrido. Memorias de un Soldado. Tomo 2, Instituto Geográfico Militar, Chile, 1991

12. Rouquié, Alain. El Estado Militar en América Latina, Siglo Veintiuno Editores, México D.F., 1984

13. Salazar, Manuel. Contreras: Historia de un Intocable, Uqbar Editores, Santiago, 2014

14. Tapia Valdés, Jorge A. La Doctrina de Seguridad Nacional en el Cono Sur. El Terrorismo de Estado. Editorial Nueva Imagen, México D.F. 1980

Fuentes:

1. Secretaría Junta de Gobierno. Acta $N^{o} 281-A$, Santiago, Septiembre de 1976

2. Defense Intelligence Agency. Biographic data on General Augusto Pinochet, Agosto-Septiembre 1973

3. Department of State, Chilean Executions, Washington, Noviembre 16 de 1973 
4. Department of the Army, FM 31-15 Operations against irregular forces, Washington D.C., 1961

5. Department of the Army. FM 19-5 The Military Policeman, Washington, 1959

6. Department of the Army. FM 30-16 Techincal Intelligence, Washington, Agosto de 1966

7. Department of the Army. FM 31-16 Counterguerrilla Operations, Washington, 1963

8. Department of the Army. FM 31-21 Guerrilla Warfare and Special Forces Operations, Washington, 1961

9. Department of the Army. FM 31-23 Stability Opertions US Army Doctrine, Washington, 1972

10. Department of the Army. FM 41-10 Civil Affair Operations, Washington, 1962

11. Department of the Army. FM 41-10 Civil Affairs Operations, Washington, 1967

12. Junta de Gobierno, Declaración de Principios 11 de Marzo, Gobierno de Chile, Santiago, 1974

13. Pinochet Ugarte, Augusto. Seguridad Nacional $N^{\circ} 2$, Academia Superior de Seguridad Nacional, Santiago, septiembre-octubre 1976 